\title{
Analysis on the Appropriate Buried Depth of the Cold-proof Drainage Hole of the Tunnel in the Cold Region
}

\author{
Maolong ZHAO*, Wei ZHU
}

\begin{abstract}
A cold-proof drainage hole is an effective measure to prevent freezing injury of a tunnel in a cold region. However, the construction technology and insulation effect of the cold-proof drainage hole only focused on existing research. This study used MIDAS/GTS for modelling based on a tunnel in cold region of Qinghai Province, China to determine the suitable buried depth of a cold-proof drainage tunnel from the mechanical properties and variation of deformation of tunnel in cold region. The working conditions of first excavating the main tunnel and then the cold-proof drainage hole were set. The variation rules of displacement, stress, and plastic zone of the main tunnel and the cold-proof drainage hole under different buried depths were analyzed. The interaction mechanism between the main tunnel and the cold-proof drainage tunnel under different buried depths was revealed. Results show that: the structure of main tunnel hole is interplayed with that of cold-proof drainage hole; from the point of displacement change rule, the optimal effective buried depth for cold-proof drainage hole of a tunnel in China's Qinghai Province is from $5 \mathrm{~m}$ to $6 \mathrm{~m}$; from the point of stress change rule, the optimal effective buried depth for the cold-proof drainage hole is also from $5 \mathrm{~m}$ to $6 \mathrm{~m}$; from the point of plastic zone change rule, the optimal effective buried depth for the cold-proof drainage hole is from $4 \mathrm{~m}$ to $6 \mathrm{~m}$ considering the stress uniformity of support and material for cold-proof drainage hole. The effective buried depth of the coldproof drainage hole is confirmed to be $5 \mathrm{~m}$. The results of finite element analysis are consistent with the field monitoring results, thereby verifying the reliability of the analytical results in this study. This study has guiding significance for the construction of the cold-proof drainage tunnel in the cold region.
\end{abstract}

Keywords: buried depth; China's Qinghai province; cold-proof drainage hole; MIDAS/GTS; tunnelling engineering

\section{INTRODUCTION}

Areas with an annual freezing depth of more than 80 $\mathrm{cm}$ are called cold region. Tunnel engineering in the cold region is a special project in infrastructural construction. A series of diseases caused by the cold environment brings not only many new problems to the engineering design and construction but also difficulties to the tunnel operation and often causes great economic losses [1-5]. A study of the formation mechanism of tunnel damage caused by repeated freezing and thawing in the cold environment is insufficient. Many engineering practices show that the solution to the problem of freezing damage prevention of tunnels in the cold region is mainly achieved through the measures of water prevention and drainage and antifreeze.

The main drainage measures of tunnels in the cold region are insulation ditch, deep buried ditch in the center, and cold-proof drainage hole [6]. The buried depth of thermal insulation ditch is shallow, and the reliability of thermal insulation is poor; consequently, the needs of drainage are difficult to meet. The center of deep buried ditch digs deep, the safety risk of construction inside the hole is great, the construction interference is great, and the later maintenance under the plateau condition is difficult. The construction of a cold-proof drainage hole will increase the investment to a certain extent. However, this approach has good reliability and little maintenance work for the plateau, cold climate conditions, and complex geological and hydrological conditions. However, construction in the cold region is difficult due to the large sectional size of the cold-proof drainage hole, and the excavation process affects the main tunnel structure, thereby increasing the difficulty of operation and maintenance of the tunnel [7, 8]. Therefore, rational evaluation of the influence of cold-proof drainage hole excavation on the main tunnel from the angle of mechanical characteristics and deformation law of tunnel in cold region is necessary to design the appropriate buried depth of the cold-proof drainage hole in the cold region [9].
The three main methods to study the mechanical properties and deformation of tunnels in the cold region are as follows: field monitoring, model test, and numerical simulation. Field monitoring requires a substantial amount of time, manpower, and expensive monitoring instruments [10]. Model tests can simulate the actual working condition and set a variety of factors and complicated boundary conditions, thereby visually revealing the changing process of a tunnel under the effect of external factors; this test is one of the effective methods to study tunnel engineering [11]. However, model tests have high requirements for model frames, similar materials, and model test methods, and they cannot effectively analyze cold region tunnel problems. The numerical simulation method has the advantages of a wide range of application, low cost of time and capital, and is easy to realize multiple boundary conditions [12].

On this basis, the excavation model of the cold-proof drainage hole was established through numerical simulation analysis. The appropriate buried depth of the cold-proof drainage hole in the cold region was determined.

This task was carried out to provide a theoretical basis for the construction of cold-proof drainage hole in the cold region.

\section{STATE OF THE ART}

The prevention and treatment of tunnel freezing damage have been a major topic in the engineering field for a long time. Tunnel workers worldwide have carried out a considerable number of basic researches and proposed many effective antifreezing measures in combination with the actual situation of their own countries. In basic research, some scholars focused on the properties of frozen soil. Inadaand Yokota [13] conducted tests on granite and andesite under several conditions of drying, one-cycle freeze-thaw cycle, and three-cycle freeze-thaw cycle through uniaxial compression and tensile tests. The result showed that the tensile and compressive strength of the 
rock under dry and saturated conditions would increase with the decrease in temperature. The content of unfrozen water in soil decreases with the increase in soil particles by using time domain reflection method to calculate the unfrozen water content in frozen soil [14]. Kozlawski [15, 16] used the interpolation scanning method to calculate and test the unfrozen water content in rock or soil. The study proposed that the calculated unfrozen water content by this method was more accurate than the other methods. Wang et al. [17] calculated the unfrozen water content by comparing the wave velocities of three types of frozen soil on the basis of previous studies. The results were in good agreement with those of Timur [18]. Other scholars focused on the temperature field of permafrost. Kaopmans and Miller [19] proposed that the ice/water two-phase coexistence in the low-temperature saturation state and the gas/water two-phase coexistence in the ordinary unsaturated state had the same mechanism. McKenzie et al. [20] proposed a formula for the relative permeability coefficient of pores in the presence of ice on the basis of this study. Bonacina and Comini [21] derived the governing equation of temperature field with the influence of phase transition and proposed a numerical solution for the problem. Comini et al. [22] carried out finite element analysis on the nonlinear problem of temperature field of heat conduction in phase transition. Nicolsky et al. [23] performed inversion analysis on the thermodynamic parameters of soil on the basis of the field measured temperature field. The development of basic theory promotes the practice of antifreezing measures. A large number of prevention and control technologies for freezing damage of tunnels in cold areas emerged at the historic moment. In foreign countries, the prevention and control measures of freezing damage in tunnels are mainly divided into passive insulation measures and active heating measures.

The passive thermal insulation measures adopt light thermal insulation material as the thermal insulation layer of the tunnel rock mass. The thickness of the thermal insulation layer needs to be increased to ensure the antifreezing effect with the decrease in ambient temperature. However, the thickness of the thermal insulation layer cannot be indefinitely increased due to environmental restrictions. An antifreeze insulation door can be installed in the entrance and exit of the tunnel to prevent cold air from invading into the tunnel and improve the average temperature inside. However, this method is only applicable to the tunnel with a small traffic flow. These passive antifreeze methods can only reduce freezing injury but cannot completely eliminate it. According to the needs, a tunnel heating system is proposed. The temperature inside the tunnel is actively increased through the heating system. The common heating system is generally driven by electricity or coal. Although the antifreeze effect is obvious, the cost is large, the environment is easy to be polluted, and the maintenance is complicated. A geothermal exchange pump system, a new energy-saving antifreeze technology, is widely used in the antifreeze insulation of tunnels in cold areas due to the increase in the environmental protection demand. Brandl [24] proposed the technology of using geothermal energy for antifreezing and thermal insulation of the tunnel. This technology uses the energy geotextile between the primary support and the secondary lining of the tunnel to collect geothermal energy of the rock mass. This energy is then lifted by a heat pump and used to heat the tunnel interior [25]. Islam et al. [26] developed a horizontal U-pipe (HUT) road heating system using a geothermal tunnel. The system utilizes sheds buried in shallow strata in the middle of the tunnel invert for heat recovery. Field tests at the Nanaori Toge tunnel show that the antifreeze pavement connected to the hut can maintain a positive temperature at the tunnel entrance. Islam et al. [27] proposed a simplified heat transfer model for the HUT system. Adam and Markiewicz and Markiewicz [28] used the finite element simulation model to optimize the economic design of the tunnel lining buried heat exchanger. In China, scholars believe that if groundwater can be removed from the surrounding rock behind the lining, then the main freezing damage will be greatly reduced or even eliminated.

At present, the main measures for the prevention and control of frost damage in tunnels in cold areas in China are: insulation ditch, deep buried ditch in the center, coldproof drainage hole, and antifreeze insulation layer.

Cold prevention and drainage tunnel can adapt to the plateau, cold climate conditions, and complex geological and hydrological conditions with good reliability and small maintenance workload. This tunnel has more advantages compared with other freezing injury prevention and control measures. A great deal of research has been conducted on the construction of cold-proof drainage tunnel with the extensive use of cold-proof drainage tunnel in China. At present, the research on cold-proof drainage tunnel mainly focuses on the following three aspects: (1) construction technology and cold-proof measures for cold-proof drainage hole: Shao and Yang [29, 30] introduced the construction methods of cold-proof drainage tunnels, thermal insulation measures, and antifreezing and expansion measures. At that time, the thermal insulation measures mainly used mobile stoves and cold-proof door technology. Liu [31] used high-pressure air and drainage pipes for heat insulation and constant-pressure water supply devices, thereby effectively guaranteeing the normal construction of large tunnels in cold areas. Du [32] and Liu [31] proposed that priority should be given to the cold-proof drainage hole. The early penetration of the coldproof drainage hole will play a leading role in the geological prediction of the tunnel engineering geological and hydrogeological conditions. The cold-proof drainage holes are connected, and a ventilator is installed in the shaft to improve the ventilation environment in the main hole. Liu [33] proposed that a cold tunnel should be equipped with a complete water-proof and drainage system, which includes water-proof and drainage facilities, such as drains, diversion tunnels, blind wells, blind ditches, and drainage boards. Hu et al. [34] carried out the construction process of the cold-proof drainage hole of the Galongla Tunnel (high-altitude cold area tunnel). The water trough is introduced into the natural gully with good geological conditions and stable surrounding rocks through the discharge tunnel, and the application effect is ideal. (2) Field investigation on the cold-proof drainage hole of tunnels in service in the cold region and evaluation on its effect: Liu et al. [35] conducted disease detection on the tunnel at Dabanshan, which has been put into operation, and confirmed the effective function of groundwater in the 
cold-proof drainage tunnel drainage hole by analyzing the causes of the disease. (3) Simulation study for temperature field of cold-proof drainage hole: Lai [36] conducted onsite temperature monitoring on the Qingshashan highway tunnel in the eastern Tibetan Plateau and studied the temperature difference distribution of the tunnel in the cold region. $\mathrm{Xu}$ [37], $\mathrm{Li}$ [38], and Liu [39] used ANSYS to simulate the temperature field of the tunnel through on-site monitoring data and studied the effects of the lining structure and thermal insulation measures. Theoretical research has confirmed the insulation effect of the coldproof drainage hole. However, few studies in theoretical research pay attention to the effect of the cold-proof drainage hole on the main tunnel structure. Liu [9] used Midas/GTS software to simulate the construction process of the cold-proof drainage hole excavation directly under the middle of two parallel tunnels. The buried depth of the cold-proof drainage hole in this special case was determined by analyzing the influence of the cold-proof drainage hole excavation on the main tunnel. Although the influence of the cold-proof drainage hole on the main tunnel is considered, this condition is particularly special. Moreover, the general cold-proof drainage hole is set directly under the tunnel, which is far from most working conditions in the actual project.

In view of the existing research deficiencies, this study uses the numerical simulation method to research the appropriate buried depth of the cold-proof drainage hole in the cold region. Numerical simulation is popular in recent years [40-42]. These methods are widely used in geotechnical engineering because they can model complex geometric models and clearly analyze the interaction between structures. In this study, Midas /GTS software was used for numerical simulation modeling, and a tunnel in a cold region of Qinghai Province was utilized as a supporting project. A numerical simulation analytical model is established on the basis of the field data of the project. This model takes into account the influence of cold-proof drainage hole excavation on the main tunnel. The cold-proof drainage hole is set directly below the main tunnel, and the working condition is to dig the main tunnel first and then the cold-proof drainage hole. The buried depth of the cold-proof drainage hole is determined by analyzing the variation of stress and strain of the main tunnel under different buried depths.

The remainder of this paper is organized as follows. Section 3 introduces the general situation of the project, establishes the numerical simulation model, and provides the model calculation parameters. Section 4 analyzes the stress-strain variation law of the main tunnel after the coldproof drainage tunnel excavation and proves the reliability of the model results through a case study. Section 5 summarizes the conclusions.

\section{METHODOLOGY}

\subsection{Overview of the Supporting Project}

The project is located approximately $10 \mathrm{~km}$ to the northeast of Xiewu town, Chengduo County, Yushu Prefecture, Qinghai Province (Fig. 1). This project is a separated tunnel. The length of the left line is $3966.0 \mathrm{~m}$. The designed road surface elevation at the entrance and exit is $4333.99-4235.74 \mathrm{~m}$. The designed vertical slope is
$-2.50 \%$. The length of the right line is $3950.00 \mathrm{~m}$. The designed road surface elevation at the entrance and exit is 4333.01-4236.26 m. The designed vertical slope is $-2.48 \%$. The axis orientation is $228^{\circ}$, the single hole design net width is $10.0 \mathrm{~m}$, and the hole net height is $8.0 \mathrm{~m}$ [43]. The buried depth of the cold-proof drainage hole is generally determined according to the maximum freezing depth of the tunnel site. Finally, the design of the coldproof drainage hole buried depth of $6.0 \mathrm{~m}$ [44]. The tunnel site is in the Sanjiangyuan area of the Tibetan plateau, where Tongtian, Zhaqu and Xiewu rivers meet. This site belongs to the structural denudation of low-mountain and hilly landform. The landform is generally from northwest to southeast with relatively large topographic undulations.

The tunnel area in the hinterland of inland plateau with high altitude is less affected by marine monsoon. This area enjoys a typical plateau continental semi-arid climate. Moreover, the area is cold, windy, and snowy in the long winter with the possibility of snow disaster. The area is cool in the short summer with abundant rainfall. Middle and high mountains are covered with frost and snow all the year round, and rainfall distribution shows obvious regional difference. Precipitation increases with the increase in altitude, while air temperature and amount of evaporation relatively decline. The four seasons are not distinctive with large temperature difference between day and night.

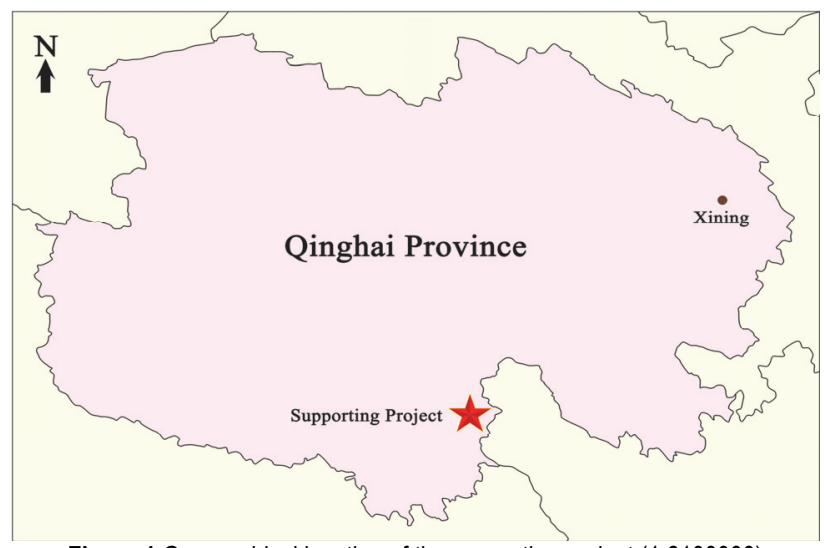

Figure 1 Geographical location of the supporting project (1:6100000)

The air is thin with low pressure and less oxygen content. The annual average temperature in the tunnel area is $-1.7{ }^{\circ} \mathrm{C}$, and the extreme maximum and minimum temperatures are $24.0{ }^{\circ} \mathrm{C}$ and $-33.0^{\circ} \mathrm{C}$, respectively. The annual average relative humidity is $81 \%$. The annual average amount of evaporation is $1649.2 \mathrm{~mm}$, and the annual frost period lasts for 7 months. The maximum snow and frost penetration depths are $14 \mathrm{~cm}$ and $3.08 \mathrm{~m}$, respectively. The site experiences abundant sunshine with an annual average sunshine rate of $50-60 \%$. In the project area, the winter is long and cold. In the tunnel construction process, severe weather environment such as cold and construction conditions have a great impact on personnel health. Construction water supply, ventilation, mechanical equipment, etc. also cannot run normally, while concrete construction will be frozen during low-temperature mixing, transportation, construction process and maintenance, so the durability of the structure cannot be guaranteed, which seriously affects the quality of the project [45]. 
The average annual precipitation in the tunnel area is approximately $615.2 \mathrm{~mm}$. The number of average annual rainy days is approximately $170 \mathrm{~d}$. The maximum monthly rainfall is approximately $425 \mathrm{~mm}$. Rain mainly comes between May and September, thereby accounting for approximately $54 \%$ of the annual rainfall. Atmospheric precipitation flows into the gully along the slope and then feeds into Xiewu River. Water from Xiewu River runs throughout the year, with more water yield in rainy season and less water yield in dry season. Xiewu River has a narrow bed and gentle flood plain.

The groundwater in the tunnel area can be divided into quaternary unconsolidated rock pore water and bedrock fissure water according to the storage conditions. The quaternary unconsolidated rock pore water is distributed in the slope and gully and stored in gravel soil and silty clay. The recharge sources include atmospheric precipitation and groundwater by lateral recharge. Bedrock fissure water is mainly stored in the fissure of sandstone-shale interbed weathered zone in Bayan Har Mountains of the Mesozoic Triassic series ( $\mathrm{T}_{3}$ by) and controlled by the thickness variation of weathered layer with good water permeability and water abundance. The recharge source is atmospheric precipitation, and the water yield greatly varies in different seasons. Groundwater is more developed, the construction process has water inrush, water surge, surface cracking, steel frame deformation, roof easy to collapse, falling block [46].

The tunnel area is mainly made of silty clay, including weathered clastic rock, with Quaternary Holocene eluvial layer $\left(Q_{4}^{e l+d l}\right)$ overlying. The Quaternary Holocene eluvial layer $\left(Q_{4}^{e l+d l}\right)$ mainly refers to silt and round gravel soil, including gravel. Grayish black sandstone-shale interbed of the Bayanharshan Group of upper Mesozoic Triassic series (T3by) lies underneath the tunnel area, and part of gully section is exposed. The tunnel area is mainly located in the head of Qinghai-Tibet-Yunnan-Burma zeta-type tectonic system and the peripheral folding belt and reconnects complex Bayan Har-Songpan arcuate tectonic belt in the north. No large fracture structure is seen in the tunnel area, and the area has a relatively stable structure. Influenced by the Xiewu Shiqu fault, F1 fault is developed in $\mathrm{k} 748+660$ of tunnel barrel. Fault F1 intersects the main line of the tunnel at a small angle, with strike of NE66 $6^{\circ}$ dip angle of $7080^{\circ}$, and fracture zone width of nearly $100 \mathrm{~m}$, The stability of surrounding rock in this section is poor, and the rock mass is gravelly. When the cavern is excavated, the top of the cavern is prone to collapse and block fall [47, $48]$.

\subsection{Basic Assumptions}

In recent years, the numerical simulation method has been widely used in geotechnical engineering. The finite element method (FEM), the finite difference method (FDM), and the boundary element method (BEM) are three common analytical methods that are popular among scholars. The FEM can make a continuous infinite degree of freedom problem become a discrete finite degree of freedom problem. However, the finite element must simultaneously solve all the nodes in the domain and boundary nodes. Many unknowns must be solved, and the equation required to be solved is large in scale, thereby resulting in many input data and a large amount of preparation work for calculation. The FDM directly starts from the differential equation, divides the solution area into grids, and uses the difference quotient to replace the differential, the microquotient. Accordingly, the infinite degree question turns into the finite freedom question. This type of method is convenient when solving the regular boundary question. However, this method is unsuitable for the irregular boundary question. The BEM takes the boundary integral equation defined on the boundary as the control equation and discretizes the boundary element by interpolation, which is converted into the algebraic equation system for solution. This method has the characteristics of combining analysis with numerical value and has high precision. The BEM is recognized as more accurate and efficient than the FEM, especially for the problems with a large gradient of change of boundary variables, such as stress concentration problem or the singular crack problem of the boundary variables. However, BEM is difficult to be applied to inhomogeneous media. In tunnel engineering, the inner boundary of the tunnel is irregular, and the surrounding rock is generally a non-uniform medium; thus, the FDM and BEM have great defects in solving this problem. In recent years, this method can make up for the shortcomings of the large amount of calculation work of the FEM with the rapid development of computer technology. Thus, the FEM is selected to analyze the tunnel engineering problems.

The following assumptions are proposed on the basis of finite element analytical software MIDAS/GTS. The main tunnel hole has a fixed location, and it has been excavated and run through. Only the buried depth of the cold-proof drainage hole needs to be adjusted. The soil constitutive model uses the Moore Coulomb model. The advantage of this model is its ability to reflect the asymmetry of the compressive and tensile strength of geotechnical materials and the sensitivity of such materials to hydrostatic pressure. The model is simple and practical. The model parameters are few, and $c$ and $\varphi$ can be measured by routine experiment. The Moore-Coulomb model can reflect the characteristics of the geotechnical materials when they are yielding, are related to the average stress and the partial stress, and are widely used. This model also has its limitations. The model reflects neither the influence of the intermediate principal stress on the yield and failure of the material nor the characteristics of hydrostatic pressure that can cause the yield of geotechnical materials. The molded yield surface has edges and corners, which are inconvenient for numerical calculation. Sprayed concrete is adopted for primary support. The weight stress field of the surrounding rock instead of the structural stress is taken into account for initial stress field. The upper boundary of the model is defined to be a free surface. The left and right boundaries are defined to be normal constraints, and the full constraint condition is employed for the lower boundary.

\subsection{Principle of Model Calculation}

The stress-strain relationship was substituted into the virtual work principle equation expressed in the form of stress variation to obtain the $\mathrm{Hu}$-Washizu variational principle: 


$$
\begin{aligned}
& \delta G_{\text {ext }}= \\
& =\int_{\Omega}(\nabla \delta u)^{\mathrm{T}} \sigma+\delta \varepsilon^{\mathrm{T}}[\sigma(\varepsilon)-\sigma]+\delta \sigma^{\mathrm{T}}(\nabla u-\varepsilon) \mathrm{d} \Omega
\end{aligned}
$$

where $\delta G_{\text {ext }}$ is the virtual work produced by an external force, $u$ is displacement, $\sigma$ is stress, $\varepsilon$ is strain, $\sigma(\varepsilon)$ is stress in terms of strain, and $\nabla$ is the stress-strain relational operator.

If the constitutive equation is assumed to always satisfy the stress-strain relationship, then the HellingerReissner variational principle can be obtained:

$$
\delta G_{\text {ext }}=\int_{\Omega}(\nabla \delta u)^{\mathrm{T}} \sigma+\delta \sigma^{\mathrm{T}}[\nabla u-\varepsilon(\varepsilon)] \mathrm{d} \Omega
$$

where $\sigma(\varepsilon)$ is strain expressed in terms of stress.

On this basis, the coordination relationship between $\varepsilon$ and $\nabla u$ can be satisfied. Eq. (2) can be changed to the general expression of virtual work principle:

$$
\delta G_{\text {ext }}=\int_{\Omega}(\nabla \delta u)^{\mathrm{T}} \sigma(u) \mathrm{d} \Omega
$$

In the FEM, the integral region of the virtual work principle is limited to a single element. The displacement is represented by the form function interpolation as follows:

$u^{h}=N d^{e}$

where $N$ is the shape function, and $d^{e}$ is the degree of freedom of cell node.

The virtual work principle equation in the element is expressed using the strain-displacement relation $\varepsilon^{k}=\nabla u^{h}$ $=B d^{e}$ :

$\delta G_{\text {ext }}=\delta d^{\mathrm{T}}\left[\sum \int_{\Omega_{e}} B^{\mathrm{T}} D B \mathrm{~d} \Omega\right] d=\delta d^{\mathrm{T}} \boldsymbol{K} d$

where $D$ is the stress-strain relationship matrix.

In the linear analysis, the total stiffness matrix $\boldsymbol{K}$ is not correlated with the node displacement $d$. The stiffness matrix $\boldsymbol{K}^{e}$ of the element is expressed in Eq. (6):

$$
\boldsymbol{K}^{\boldsymbol{e}}=\int_{\Omega_{e}} B^{\mathrm{T}} D B \mathrm{~d} \Omega
$$

The two types of elements in the model are three-node triangle and four-node quadrilateral elements. The shape functions of these two types of elements are shown as follows: Eq. (7) is the shape function of three-node triangle element; Eq. (8) is the shape function of four-node quadrilateral element. The shape function in the equation is expressed in the natural coordinate system $(\xi, \eta, \zeta)$ :

$N_{1}=1-\xi-\eta, \quad N_{2}=\xi, \quad N_{3}=\eta$

$N_{i}=\frac{1}{4}\left(1+\xi_{i} \xi\right)\left(1+\eta_{i} \eta\right)$

\subsection{Modeling}

Considering the coverage of tunnel, the left and right boundaries of the model are 3-5 times the tunnel diameter from the side of tunnel contour line. The lower boundary is 3-5 times the tunnel height from the bottom of tunnel contour line. The upper boundary is $25 \mathrm{~m}$ from the upper part of tunnel contour line, which is equal to the average buried depth. The model dimension is $110 \times 75 \mathrm{~m}$. The model consists of 4035 quadrilateral plane elements with 4204 nodes. The size of the grid far from the tunnel is $1 \times$ $1 \mathrm{~m}$. The position close to the tunnel is an irregular quadrilateral grid automatically encrypted by software. Only gravity field is applied during the model calculation. The setting of the main tunnel and cold-proof drainage holes is shown in Fig. 2. The model meshing is demonstrated in Fig. 3.

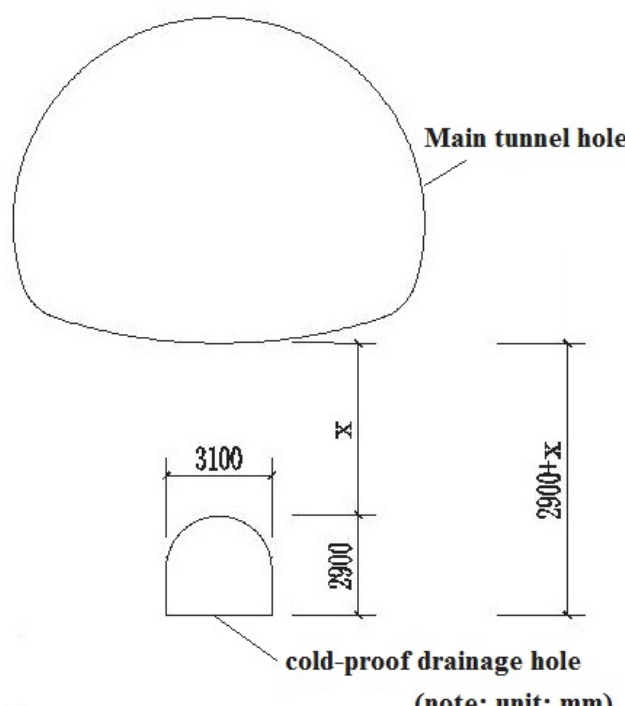

Note: $X$ means the effective buried depth of the cold-proof drainage hole, and $2900+X$ refers to the buried depth of cold-proof drainage hole.

Figure 2 Schematic of the main tunnel and cold-proof drainage holes (unit: $\mathrm{mm}$ )

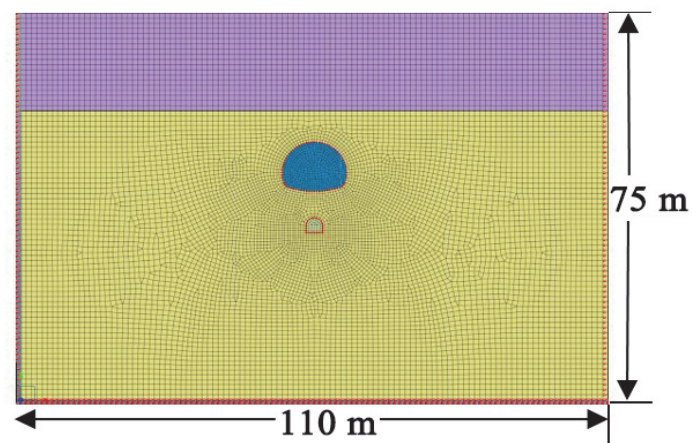

Figure 3 Model meshing map

In a tunnel in China's Qinghai Province, construction of cold-proof drainage hole is implemented after the excavation of main tunnel hole. Tab. 1 illustrates the construction stage division and stress release coefficient value. The scheme design of buried depth of cold-proof drainage hole is shown in Tab. 2.

\subsection{Parameter Determination}

The mechanical parameters for surrounding rock materials selected are shown in Tab. 3 . 
Table 1 Construction stage division and stress release coefficient value

\begin{tabular}{|c|l|c|}
\hline Stage & \multicolumn{1}{|c|}{ Construction conditions } & $\begin{array}{c}\text { Stress release } \\
\text { coefficient }\end{array}$ \\
\hline 1 & $\begin{array}{l}\text { Initial state (excavation of the main tunnel hole is completed; primary support has been provided; stress state is kept; and } \\
\text { displacement is reset) }\end{array}$ & 0.4 \\
\hline 2 & Cold-proof drainage hole is excavated & 0.3 \\
\hline 3 & The cold-proof drainage hole is supported & 0.3 \\
\hline
\end{tabular}

Note: Given that stress release is not instantaneous during tunnel excavation, the concept of stress release coefficient is introduced to simulate the process. The stress release coefficient refers to the ratio of effective and initial deformation moduli of the surrounding rock after excavation.

Table 2 Table of scheme design

\begin{tabular}{|c|c|c|c|c|c|}
\hline Schemeno. & Effective buried depth $X / \mathrm{m}$ & Burieddepth $(2.9+X) / \mathrm{m}$ & Schemeno. & Effective buried depth $X / \mathrm{m}$ & Burieddepth $(2.9+X) / \mathrm{m}$ \\
\hline $\mathrm{a}$ & 2.1 & 5 & $\mathrm{e}$ & 6.1 \\
\hline $\mathrm{b}$ & 3.1 & 6 & $\mathrm{f}$ & 9 \\
\hline $\mathrm{c}$ & 4.1 & 7 & $\mathrm{~g}$ & 7.1 & 8.1 \\
\hline $\mathrm{d}$ & 5.1 & 8 & $\mathrm{~h}$ & 10 & 9.1 \\
\hline
\end{tabular}

Table 3 Mechanical parameters of the surrounding rock materials [43]

\begin{tabular}{|l|c|c|c|c|c|}
\hline \multicolumn{1}{|c|}{ Type of materials } & Weight $/ \mathrm{kNm}^{-3}$ & Elasticity modulus $/ \mathrm{MPa}$ & Poisson's ratio & Cohesion $/ \mathrm{kPa}$ & Internal friction angle $/{ }^{\circ}$ \\
\hline Silty clay & 18.7 & 200 & 0.35 & 80 \\
\hline Sandstone-shale interbed & 19.5 & 1100 & 0.4 & 23 \\
\hline Primary support & 25 & 25000 & 0.2 & 160 \\
\hline
\end{tabular}

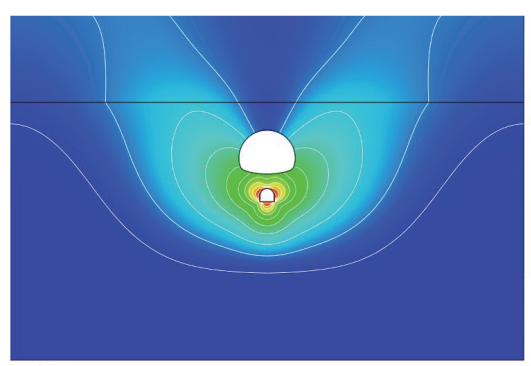

unit: $\mathrm{m}$

(a) Effective buried depth is $2.1 \mathrm{~m}$

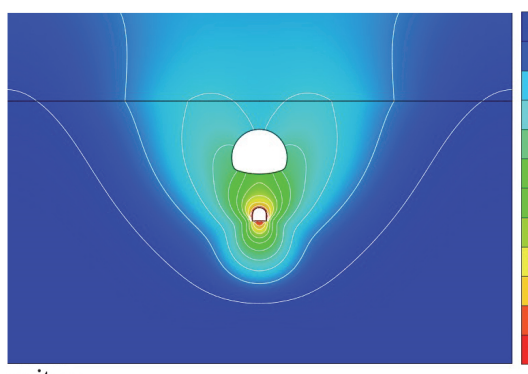

(c) Effective burieddepth is $4.1 \mathrm{~m}$

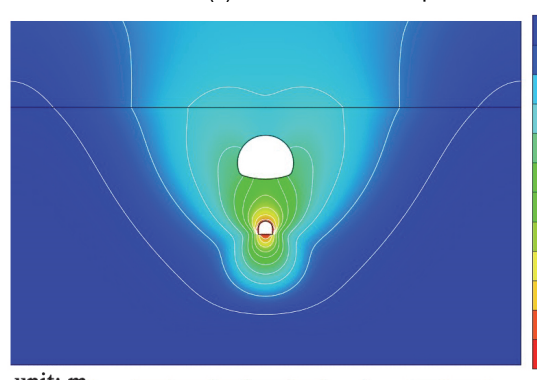

(e) Effective buried depth is $6.1 \mathrm{~m}$

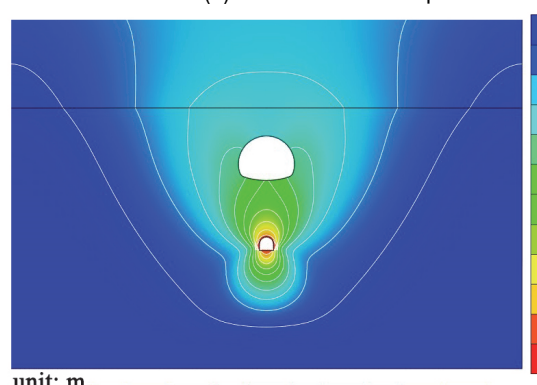

unit: $\mathrm{m}$

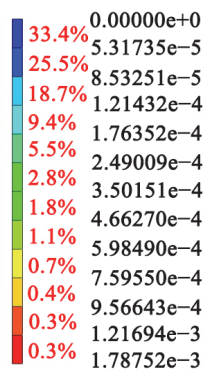

$34.1 \% 0.00000+0$ $34.1 \% 7.48273 \mathrm{e}-5$ $23.1 \% 1.31189 \mathrm{e}-4$ $19.8 \% \frac{1.31189 \mathrm{e}-4}{1.89739 \mathrm{e}-4}$ $10.1 \% 2.63493 \mathrm{e}-4$ $5.0 \% \quad 3.68584 \mathrm{e}-4$ $2.5 \% \quad \begin{aligned} & 3.68584 \mathrm{e}-4 \\ & 5.05521 \mathrm{e}-4\end{aligned}$ $2.1 \% \quad 6.05521 \mathrm{e}-4$ $1.4 \% \quad 6.51340 \mathrm{e}-4$ $0.8 \% \quad 8.41833 \mathrm{e}-4$ $0.8 \% \quad 1.10209 \mathrm{e}-3$ $0.3 \% \quad 1.44718 \mathrm{e}-3$ $0.3 \% \quad 1.88143 \mathrm{e}-3$ $2.85706 \mathrm{e}-3$
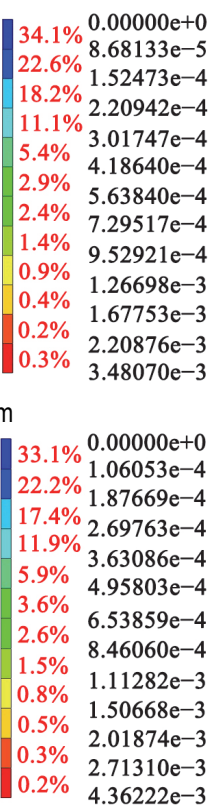

(g) Effective buried depth is $8.1 \mathrm{~m}$

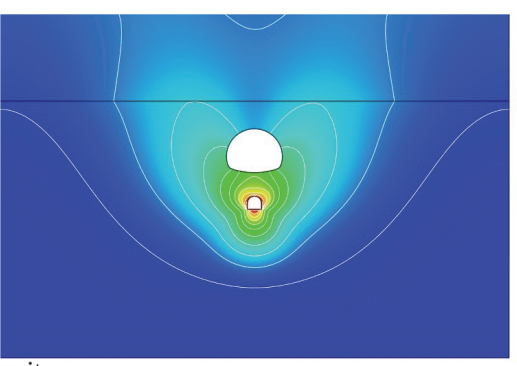

$33.5 \% 0.00000 \mathrm{e}+0$ $24.2 \% 6.29959 \mathrm{e}-5$ $24.2 \% 1.10436 \mathrm{e}-4$ $20.6 \% 1.55205 \mathrm{e}-4$ $9.4 \% \quad 2.20275 \mathrm{e}-4$ $5.1 \% \quad 3.09918 \mathrm{e}-4$ $2.5 \% \quad 3.09918 \mathrm{e}-4$ $1.8 \% \quad 4.27189 \mathrm{e}-4$ $1.8 \% 5.59623 \mathrm{e}-4$ $1.2 \% \quad 7.23596 \mathrm{e}-4$ $0.7 \% \quad 9.37773 \mathrm{e}-4$ $0.4 \% \quad 1.21322 \mathrm{e}-3$ $0.3 \% \quad 1.56773 \mathrm{e}-3$ $0.3 \% \quad \begin{array}{ll}1.56773 \mathrm{e}-3 \\ 2.36429 \mathrm{e}-3\end{array}$ unit: $\mathrm{m}$

(b) Effective buried depth is $3.1 \mathrm{~m}$

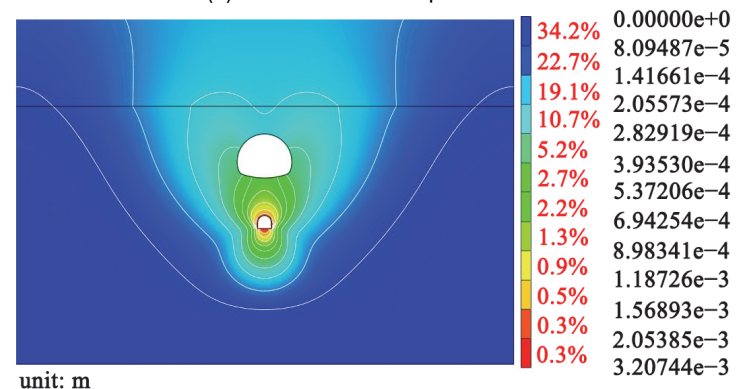

(d) Effective buried depth is $5.1 \mathrm{~m}$

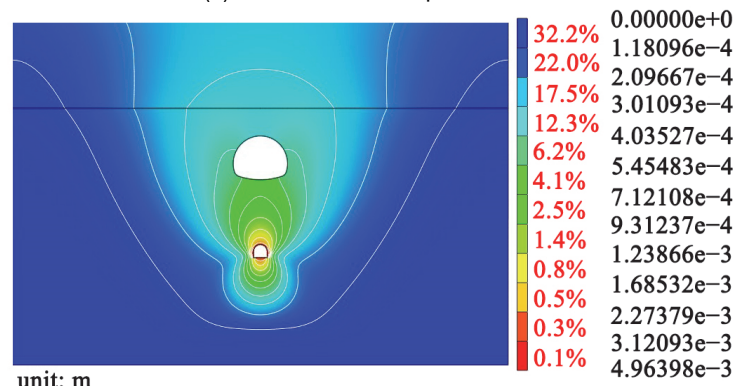

(f) Effective buried depth is $7.1 \mathrm{~m}$

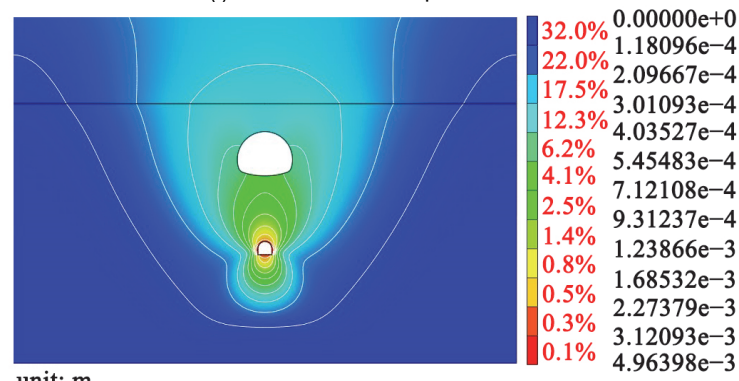

(h) Effective buried depth is $9.1 \mathrm{~m}$

Figure 4 Contours of displacement in the cold-proof drainage hole with different buried depths (unit: $\mathrm{mm}$ ) 


\section{RESULT ANALYSIS AND DISCUSSION 4.1 Variation of Displacement}

The initial displacement is reset to analyze the variation of displacement in the cold-proof drainage hole with different buried depths. The contours of displacement in the cold-proof drainage hole with different buried depths are shown in Fig. 4. The figure demonstrates that if the buried depth of the cold-proof drainage hole is large, then the isoline of displacement is less affected. When the effective buried depth of the cold-proof drainage hole is 5$6 \mathrm{~m}$ (the buried depth is 8-9 $\mathrm{m}$ ), the excavation of the coldproof drainage hole basically exerts no influence on the isoline of displacement.

Fig. 5 shows the vertical displacement variation of the various control points of the main tunnel hole with different buried depths. The figure shows that when the cold-proof drainage hole has different buried depths, the vertical displacement variation for the various control points of the main tunnel hole indicates the same trend. In terms of the influence extent, the arch bottom has the largest settlement, followed by the arch springing and crown. Before the effective depth of the cold-proof drainage tunnel is $4 \mathrm{~m}$, the displacement change rate of the main tunnel is relatively large. When the effective depth of the tunnel is 4-7 $\mathrm{m}$, the change rate becomes small and demonstrates a gentle stage. When the effective buried depth of the cold-proof drainage tunnel is greater than $4 \mathrm{~m}$, the arch bottom displacement of the main tunnel basically tends to a constant value with the increase in buried depth.

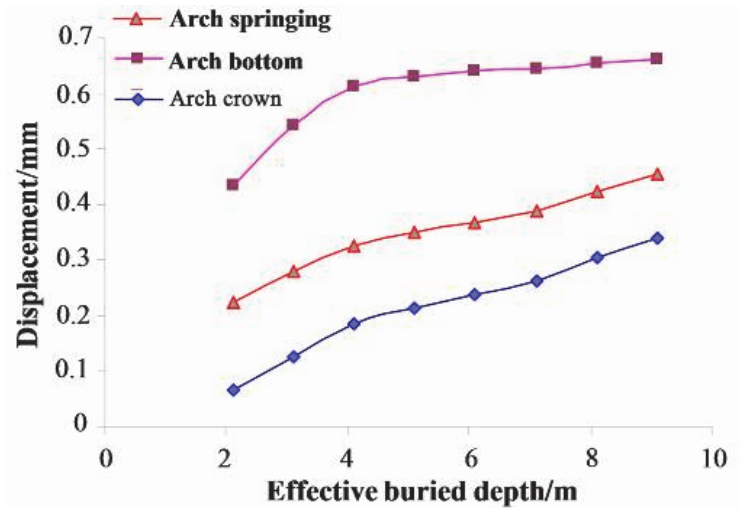

Figure 5 Displacement of various control points for the main tunnel hole with different buried depths

Fig. 6 shows the vertical displacement variation of the various control points of the cold-proof drainage hole with different buried depths below the main tunnel hole. The figure shows that when the effective buried depth of the cold-proof drainage hole is less than $4 \mathrm{~m}$, the settlement of various control points is less. The settlement has a big rate of variation because the primary support on the arch bottom of main tunnel hole serves as a lintel for the structure of the cold-proof drainage hole. When the effective buried depth is between $4 \mathrm{~m}$ and $7 \mathrm{~m}$, the settlement of various control points varies at a small rate and becomes gentle due to the small influence of lintel at the arch bottom of main tunnel hole. When the effective buried depth of the cold-proof drainage hole is more than $7 \mathrm{~m}$, the settlement of various control points varies at a huge rate due to the large burial depth of stratum. The influence of lintel at the arch bottom of main tunnel hole has basically disappeared.

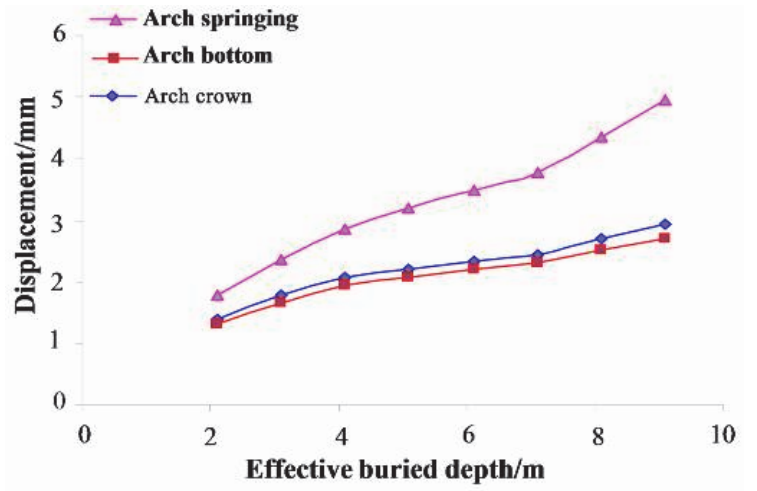

Figure 6 Displacement of various control points for the cold-proof drainage hole with different buried depths

The analysis of the variation law for the displacement of the cold-proof drainage hole with different buried depths indicates that the structure of main tunnel hole is interplayed with that of the cold-proof drainage hole. The optimal period to control the main tunnel and cold-proof drainage holes is when the effective buried depth of the cold-proof drainage hole is between $5 \mathrm{~m}$ and $6 \mathrm{~m}$.

\subsection{Variation of Stress}

The stress field in the initial state of the model is shown in Fig. 7. The distribution of the horizontal and vertical stresses in the model accords with the general law. In this model, the lateral pressure coefficient $\mathrm{K}$ of soil ranges from 0.39 to 0.65 . The lateral pressure coefficients at the top and bottom of the model are 0.40 and 0.65 , respectively. This result is due to the following: the top soil layer is subject to less pressure of the overlying soil layer; and the bottom soil layer is subject to great pressure of the upper soil layer in the numerical simulation of the stress field. The empirical value given by Engineering Geology Manual (China) illustrates that the lateral pressure coefficient of silty clay is between 0.33 and 0.53 , and that of clay is between 0.33 and 0.72. In the field work, soil classification and designation are generally identified by the naked eye, and silty clay and clay are relatively similar. The results of the phase field work may not be completely accurate. The numerical simulation was carried out according to the measured physical indexes of the soil. Under the stress state of the initial model, the value of the lateral pressure coefficient of the soil was consistent with the value range of silty clay and clay. Therefore, the model established in this study was consistent with the reality.

Fig. 8 is the stress distribution diagram after the excavation of the cold-proof drainage hole under the condition of effective embedment of $2.1 \mathrm{~m}$. The figure demonstrates that the stress distribution at the arch crown of the main tunnel has basically no change after the excavation of the cold-proof drainage hole compared with Fig. 7. The stress concentration range at the arch springing slightly increases, and the obvious unloading phenomenon occurs at the arch bottom, thereby leading to a large displacement. This result is consistent with Fig. 5. The displacement of the control point in the main tunnel is as follows: arch bottom $>$ arch springing $>$ arch crown. The 
horizontal stress of the two sides of the cold-proof drainage hole becomes small. The vertical stress of the arch crown and the arch bottom becomes smaller, and they are in the unloading state. The stress distribution law of surrounding rock around the cold-proof drainage hole is consistent with the displacement distribution law in Fig. 6. The displacement of the surrounding rock around the coldproof drainage hole is large, which is caused by the unloading of surrounding rock after the excavation of the cold-proof drainage hole.

Fig. 9 shows the stress of various control points for the main tunnel hole with different buried depths. The figure shows that the first principal stress for the arch crown of the main tunnel hole remains the same because the excavation of the cold-proof drainage hole exerts less influence on it due to the primary support of main tunnel hole. Excavation of the cold-proof drainage hole has a bigger influence on the first principal stress for the arch bottom and arch springing of the main tunnel hole compared with the arch crown. The first principal stress shows a valley value when the valid buried depth of the cold-proof drainage hole is 5-6 $\mathrm{m}$ with the increase in the buried depth of the cold-proof drainage hole. Fig. 9 indicates that the third principal stress for the arch springing of the main tunnel hole increases with the increase in the buried depth of the cold-proof drainage hole. However, the third principal stress becomes gentle when the effective buried depth is approximately $4-7 \mathrm{~m}$. The arch crown and bottom of the main tunnel hole show obvious regular variation. The third principal stress shows a valley value when the valid buried depth is 4-7 $\mathrm{m}$ with the increase in the buried depth of the cold-proof drainage hole.

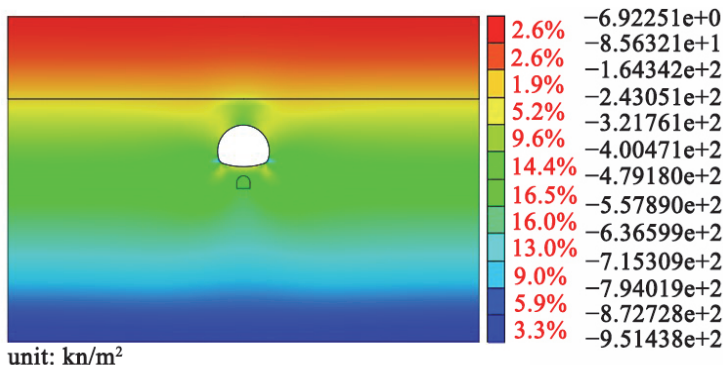

(a)

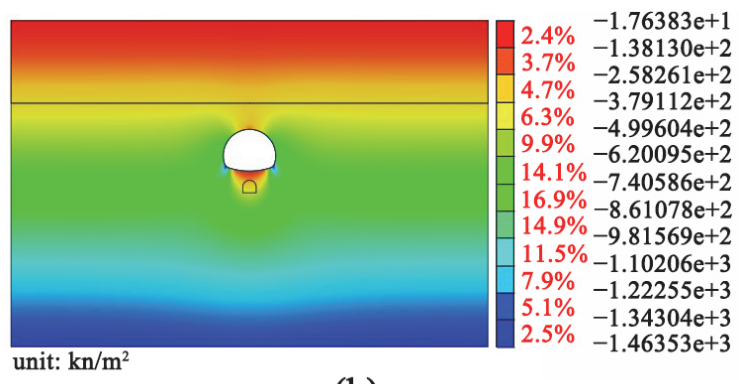

(b)

Figure 7 Stress field distribution of the surrounding rock after the main tunnel excavation: (a) horizontal direction; (b) vertical direction

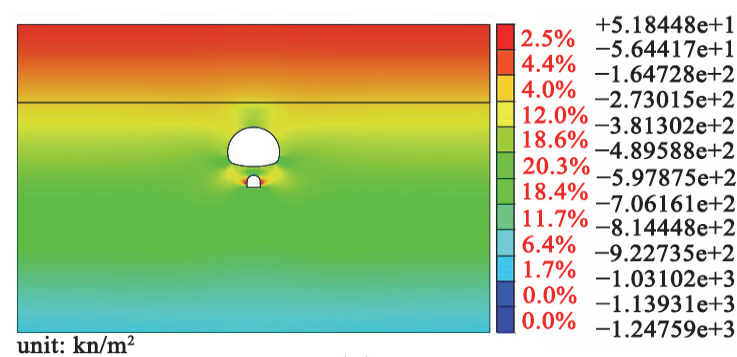

(a)

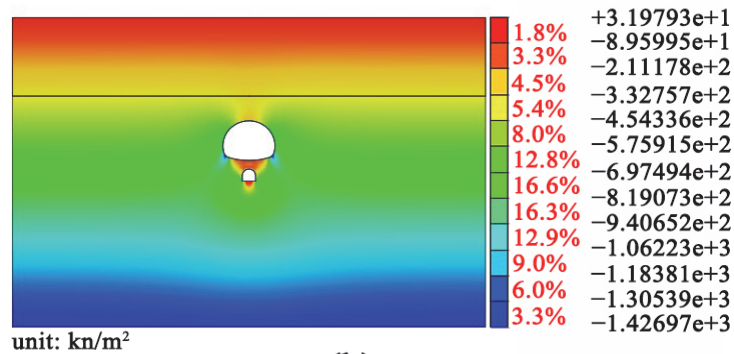

(b)

Figure 8 Stress distribution after the cold-proof drainage hole excavation when the effective buried depth is $2.1 \mathrm{~m}$ : (a) horizontal direction; (b) vertical direction
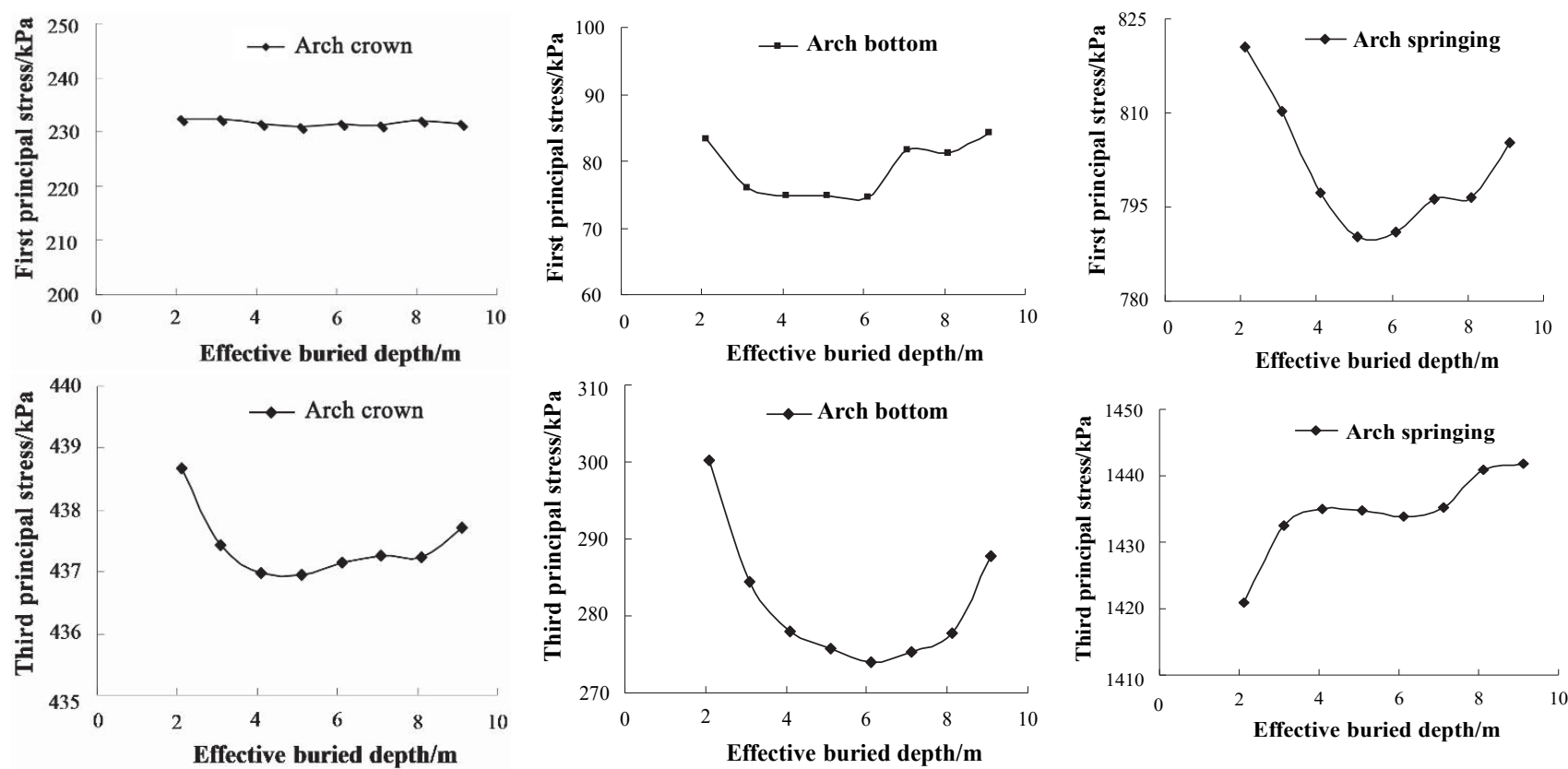

Figure 9 Stress for various control points of the main tunnel hole with different buried depths 
Fig. 10 shows the stress for various control points of the cold-proof drainage hole with different buried depths below the main tunnel hole. The figure demonstrates that the first principal stress of the arch crown of the cold-proof drainage hole shows a great variation when the effective buried depth is $4 \mathrm{~m}$. The first principal stress becomes stable when the effective buried depth is $5-8 \mathrm{~m}$. When the effective buried depth is $4-7 \mathrm{~m}$, the first principal stress of the arch springing of the cold-proof drainage hole shows a valley value. When the effective buried depth is 4-6 $\mathrm{m}$, the first principal stress of the arch springing of the cold-proof drainage hole is stable. Based on Fig. 7, the third principal stress of the arch crown and bottom of the cold-proof drainage hole show variation when the effective buried depth is $4 \mathrm{~m}$. The third principal stress becomes stable when the effective buried depth is $4-8 \mathrm{~m}$. The third principal stress of the arch springing of the cold-proof drainage hole increases with the increase in the buried depth of the cold-proof drainage hole. Moreover, the third principal stress of the arch springing of the cold-proof drainage hole shows fluctuation when the effective buried depth is $4-7 \mathrm{~m}$.

The analysis of the variation law for the displacement of the cold-proof drainage hole with different buried depths indicates that the structure of the main tunnel hole is interplayed with that of the cold-proof drainage hole. The optimal period to control the main tunnel and cold-proof drainage holes is when the effective buried depth of the cold-proof drainage hole is between $5 \mathrm{~m}$ and $6 \mathrm{~m}$.

\subsection{Variation of Plastic Zone}

Fig. 11 shows the contours of plastic zone for the coldproof drainage hole with different buried depths. The figure demonstrates that the stress concentration and loading state occur at the arch springing of the main tunnel when the cold-proof drainage hole is excavated at different buried depths, which is the result of stress redistribution at the bottom of the main tunnel caused by the cold-proof drainage hole excavation. The stress concentration range of the arch springing of the main tunnel slightly increases with the increase in the buried depth, thereby leading to tensile failure. This phenomenon is because of the small principal stress difference at the arch springing when the buried depth is relatively shallow. The principal stress difference slightly increases and gradually stabilizes with the increase in the buried depth. The arch springing and two side walls of the cold-proof drainage hole decrease after stress redistribution. Accordingly, the arch springing, arch bottom, and side wall of the cold-proof drainage hole are in the unloading state. Under different buried depths, the plastic area of the tunnel increases with the buried depth. This phenomenon is because of the surrounding rock beneath the main tunnel that has been unloaded once after the completion of the excavation of the main tunnel before the excavation of the cold-proof drainage hole. The distance between the cold-proof drainage hole and the main tunnel is small. The stress redistribution of the arch crown after the excavation of the cold-proof drainage hole slightly changes; thus, the displacement of the arch crown is small. The influence of the main tunnel on the cold-proof drainage hole slowly decreases with the increase in the buried depth. Accordingly, the displacement of the surrounding rock around the cold-proof drainage hole gradually expands, thereby leading to the continuous increase of the failure range in the surrounding rock of the cold-proof drainage hole. Specifically, the plastic zone symmetrically develops along both sides toward the arch springing.

The analysis of the variation law of the plastic zone for the cold-proof drainage hole with different buried depths indicates that the structure of main tunnel hole is interplayed with that of the cold-proof drainage hole. The buried depth scheme with a uniform distribution of the plastic zone is selected considering the stress uniformity of the support and material for cold-proof drainage hole. Specifically, the optimal period to control the main tunnel and cold-proof drainage holes is when the effective buried depth of the cold-proof drainage hole is 4-6 m.
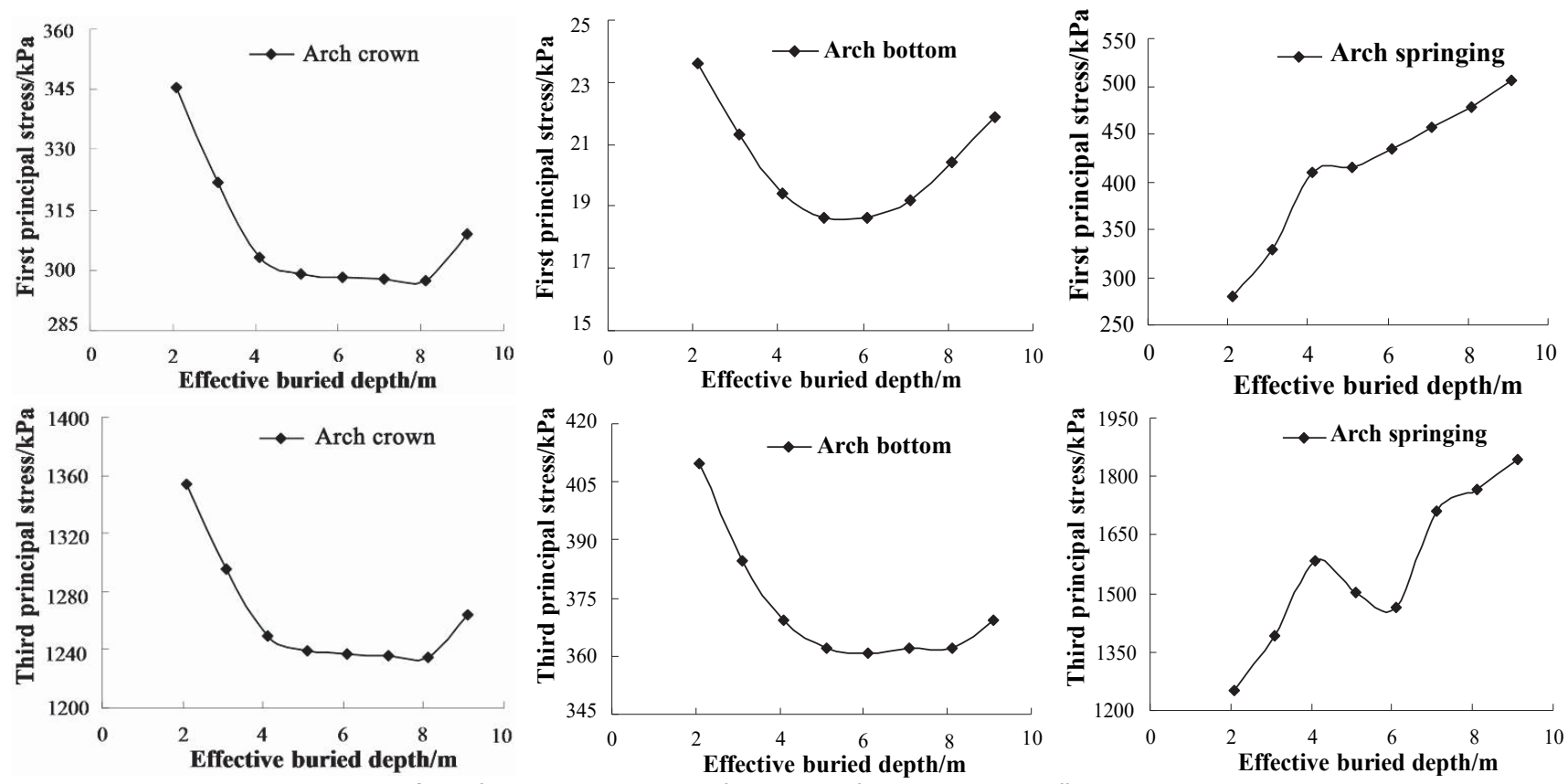

Figure 10 Stress for various control points of the cold-proof drainage hole with different buried depths 


\subsection{Verification of the Numerical Simulation Results}

In the construction stage, the stress of the main tunnel is monitored. The monitoring results are shown in Fig. 12 [43]. The figure demonstrates that the position with the largest stress after the excavation of the main tunnel is the left arch springing, followed by the spandrel, which is consistent with the stress distribution law of the surrounding rock of the tunnel shown in Fig. 7. However, the field monitoring results show that the stress value of the right arch springing is significantly lower than that of the left arch springing, and even a negative value appears in certain positions. This phenomenon is due to the occurrence of hollowing because the shotcrete is light and insufficient contact. Consequently, tensile stress will occur, which will be extremely adverse to the initial support of the tunnel, and it is a key problem to be prevented in the construction. In an ideal case, the stress distribution of the left and right arch legs of the tunnel should be symmetrical. Therefore, the numerical simulation model established in this study is highly consistent with the actual project, which can play a guiding role for similar projects.

\section{CONCLUSIONS}

The construction conditions of first excavating the main tunnel and then the cold-proof drainage hole were modeled by Midas/GTS software in this study based on a tunnel in the cold region of Qinghai Province to determine the suitable buried depth of the cold-proof drainage hole. The variation of displacement, stress, and plastic zone of the main tunnel and cold-proof drainage hole under different buried depths are analyzed. The conclusions are as follows:

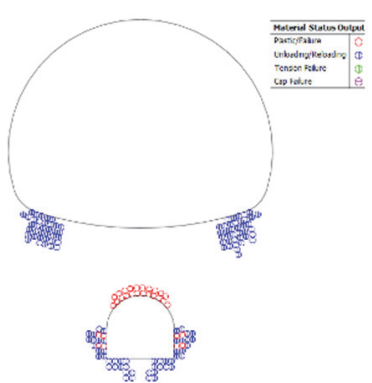

(a) Effective buried depth is $2.1 \mathrm{~m}$
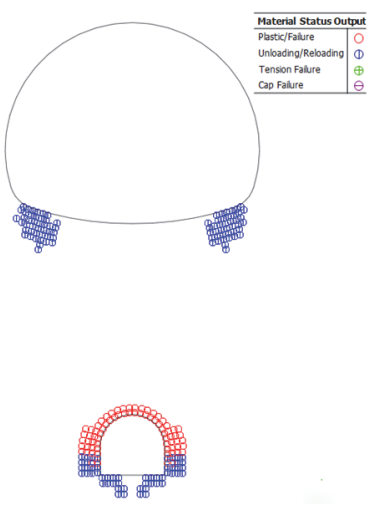

(e) Effective buried depth is $6.1 \mathrm{~m}$

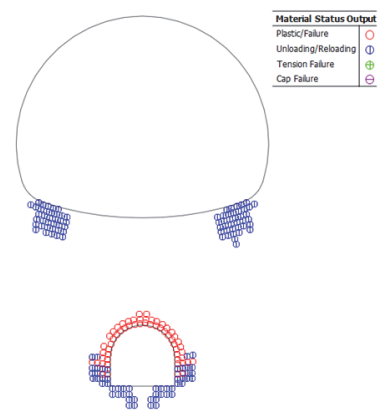

(b) Effective buried depth is $3.1 \mathrm{~m}$
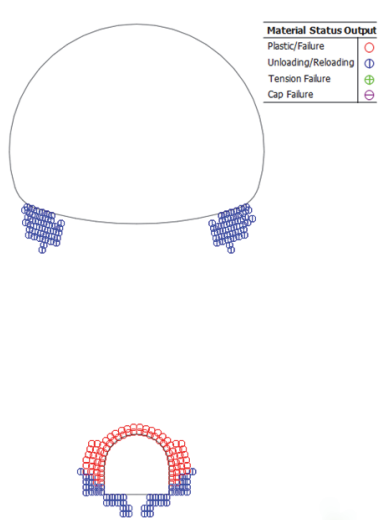

(f) Effective buried depth is $7.1 \mathrm{~m}$

Figure 11 Contours of the plastic zone for cold-proof

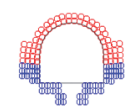

(c) Effective buried depth is $4.1 \mathrm{~m}$

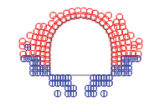

(g) Effective buried depth is $8.1 \mathrm{~m}$
(1) The structural influence between the main tunnel and the cold-proof drainage hole is mutual.

(2) The influence of the main tunnel is small when the depth of the cold-proof drainage hole is great. After the excavation of the tunnel, the displacement of the main tunnel is big, and the tunnel is at the arch springing. The stress concentration in the arch springing of the main tunnel is in the loading state. The stress concentration range of the arch springing of the main tunnel slightly increases with the increase in the buried depth. The plastic zone of the surrounding rock around the tunnel increases with the increase in the buried depth and develops from the vault to the tunnel.

(3) The displacement of main tunnel and cold-proof drainage hole gradually increases with the increase in the buried depth. The maximum displacement in the main tunnel is $0.68 \mathrm{~mm}$ at the arch bottom, $0.40 \mathrm{~mm}$ at the arch foot, and $0.36 \mathrm{~mm}$ at the arch bottom. The maximum displacement in the cold-proof drainage hole is $2.74 \mathrm{~mm}$ at the arch bottom, $4.96 \mathrm{~mm}$ at the arch foot, and $2.86 \mathrm{~mm}$ at the arch bottom. The maximum principal stress difference between the main tunnel and the cold-proof drainage hole occurs at the arch foot. When the effective buried depth of the cold-proof drainage hole is $5 \mathrm{~m}$, the principal stress difference of the arch foot of the main tunnel reaches the maximum value of $645 \mathrm{kPa}$. When the effective buried depth of the cold-proof drainage hole is $9 \mathrm{~m}$, the principal stress difference of the arch foot of the cold-proof drainage hole reaches a maximum value of $1400 \mathrm{kPa}$.

(4) Considering the large frozen depth, the requirements of safety and economy, and the influencing factors of the construction of the tunnelling engineering area, the proper effective buried depth of the cold-proof drainage hole is confirmed to be $5 \mathrm{~m}$. The proper buried depth of cold-proof drainage hole is confirmed to be $8 \mathrm{~m}$.
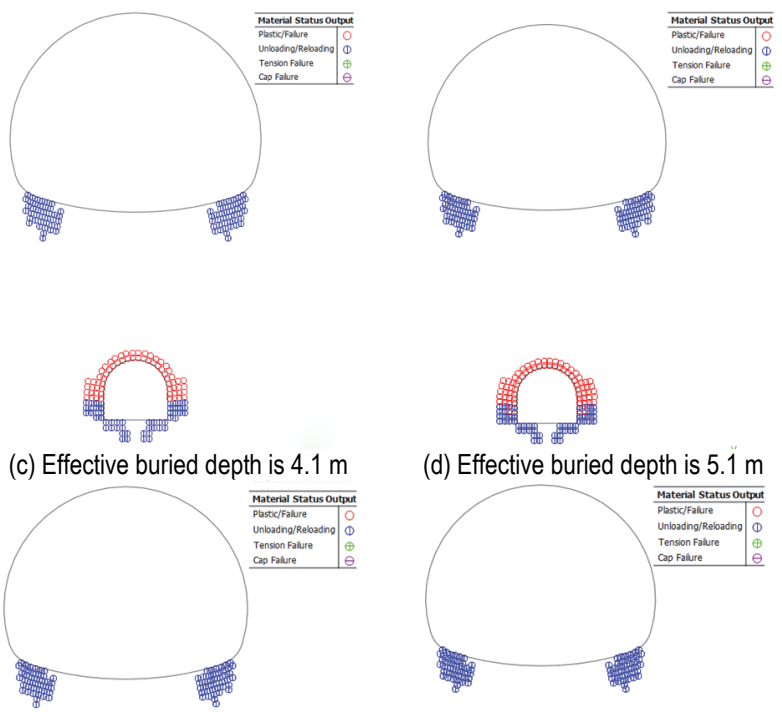

(d) Effective buried depth is $5.1 \mathrm{~m}$

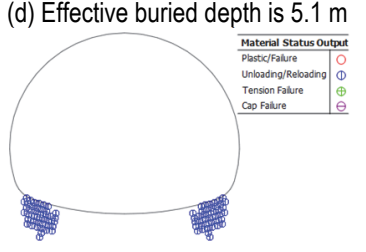

(h) Effective buried depth is $9.1 \mathrm{~m}$ 


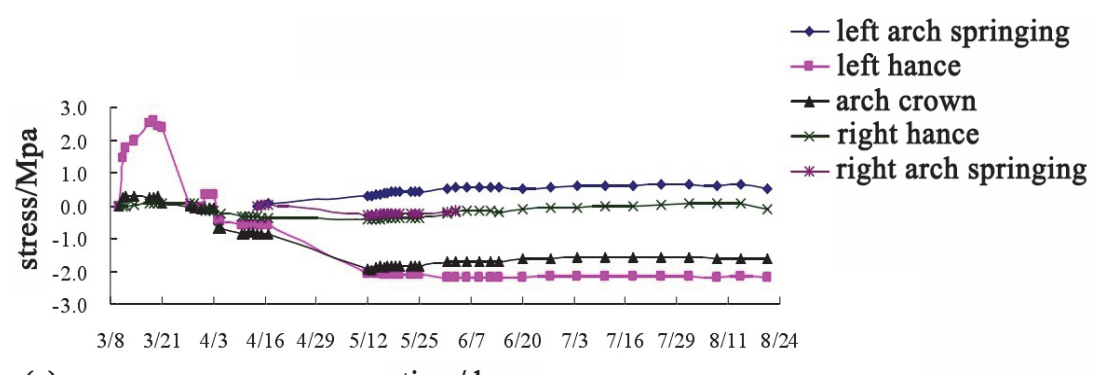

(a)

time/d

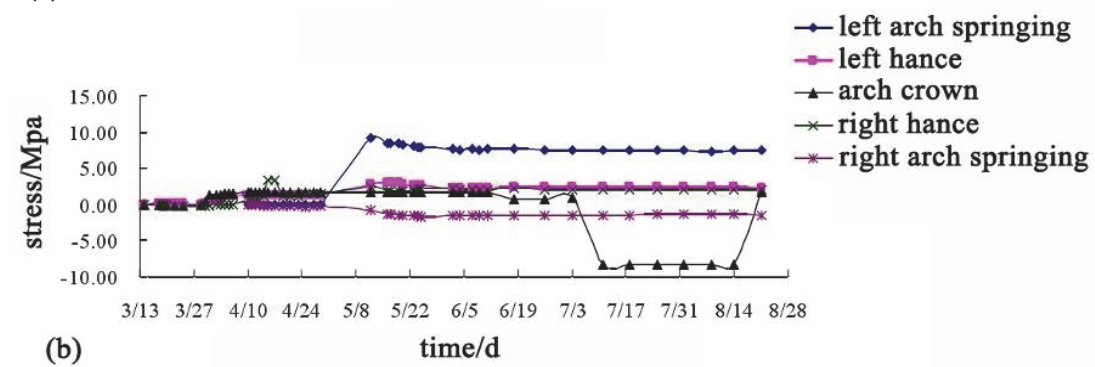

Figure 12 Stress monitoring during construction of Yankoushan tunnel: (a) section YK746+357; (b) section YK746+757 [43]

The influence of cold-proof drainage hole excavation on the main tunnel was analyzed in this study. Accordingly, the appropriate buried depth of cold-proof drainage hole was determined, which has guiding significance for similar projects. Only the stress and strain of the rock and soil mass were considered in the analytical model in this study. However, this study did not consider the influence of seepage and temperature fields. The main tunnel was first excavated, followed by the cold-proof drainage hole. In future research, multifield coupling should be conducted, and additional working conditions should be designed according to the site construction conditions.

\section{REFERENCES}

[1] Feng, Q., Jiang, B. S., Zhang, Q., \& Wang L. P. (2014). Analytical Elasto-plastic Solution for Stress and Deformation of Surrounding Rock in Cold Region Tunnels. Cold Regions Science and Technology, 108, 59-68. https://doi.org/10.1016/j.coldregions.2014.08.001

[2] Gao, G. Y., Chen, Q. S., Zhang, Q. S., \& Chen, G. Q. (2011). Analytical Elasto-plastic Solution for Stress and Plastic Zone of Surrounding Rock in Cold Region Tunnels. Cold Regions Science and Technology, 72, 50-57. https://doi.org/10.1016/j.coldregions.2011.11.007

[3] Zhang, X. F., Lai, Y. M., Yu, W. B., Zhang, S. J., \& Xiao, J. Z. (2004). Forecast Analysis of The Refreezing of Kunlun Mountain Permafrost Tunnel on Qing-Tibet Railway in China. Cold Regions Science and Technology, 39(1), 19-31. https://doi.org/10.1016/j.coldregions.2009.06.001

[4] Zhang, X. F., Lai, Y. M., Yu, W. B., \& Zhang, S. J. (2002). Non-linear Analysis for the Freezing-thawing Situation of the Rock Surrounding the Tunnel in Cold Regions Under the Conditions of Different Construction Seasons, Initial Temperatures and Insulations. Tunnelling and Underground Space Technology, 17(3), 315-325. https://doi.org/10.1016/S0886-7798(02)00030-5

[5] Lai, Y. M., Wu, Z. W., Zhu, Y. L., \& Zhu, L. N. (1998). Nonlinear Analysis for the Coupled Problem of Temperature, Seepage and Stress Fields in Cold-region Tunnels. Tunnelling and Underground Space Technology, 13(4), 435-440. https://doi.org/10.1016/S0886-7798(98)00086-8

[6] Wang, P. A., Tan, Z. S., \& Ren, S. Q. (2017). Prevention technology of freezing injure in water-rich high speed railway tunnels in plateau cold regions. China Civil Engineering Journal, 50(S2), 231-235.

[7] Gao, Y., Zhu, Y. Q., Zhao, D. P., Geng, J. Y., \& Xin, H. (2018). Study on classified suggestion of tunnel in cold region and thermal insulation-considered drainage technology. Chinese Journal of Rock Mechanics and Engineering, 37(S1), 3489-3499.

[8] Sun, K. G., Yang, P., Qiu, W. G., Song, X. H., Lin, L. B., \& $\mathrm{Xu}, \mathrm{W}$. P. (2017). Research on the Temperature Field and the Buried Depth of Drains for Tunnels in Cold Region. Journal of Railway Engineering Society, 34(4), 51-57.

[9] Liu, L. W., He, W. S., Lu, S. Y., \& Zeng, X. X. (2018). Numerical analysis of appropriate buried position for coldproof drainage hole of Dangjinshan tunnel. Railway Standard Design, 62(4), 130-135.

[10] Zhao, P. Y., Chen, J. X., Luo, Y. B., Li, Y., Chen, L. J., Wang, C. W., \& Hu, T. T. (2020). Field measurement of air temperature in a cold region tunnel in northeast China. Cold Regions Science and Technology, 171, 102957. https://doi.org/10.1016/j.coldregions.2019.102957

[11] Liu, L. L., Li, Z., Liu, X. Y., \& Li, Y. Y. (2018). Frost front research of a cold-region tunnel considering ventilation based on a physical model test. Tunnelling and Underground Space Technology, 77, 261-279. https://doi.org/10.1016/j.tust.2018.04.011

[12] Feng, Q., Fu, S. G., Wang, C. X., Liu, W. W., Wang, Y. \& Qiao, W. G. (2019). Analytical Elasto-plastic Solution for Frost Force of Cold-Region Tunnels considering Anisotropic Frost Heave in the Surrounding Rock. KSCE Journal of Civil Engineering, 23(9), 3831-3842. https://doi.org/10.1007/s12205-019-1446-7

[13] Inada, Y. \& Yokota, K. (1984). Some studies of low rock strength. International Journal of Rock Mechanics and Mining Sciences \& Geomechanics Abstracts, 21(3), 145153. https://doi.org/10.1016/0148-9062(84)91532-8

[14] Christ, M. \& Kim, Y. C. (2009). Experimental study on the physical-mechanical properties of frozensilt. KSCE Journal of Civil Engineering, 13(5), 317-324. https://doi.org/10.1007/s12205-009-0317-z

[15] Kozlowski, T. (2007). A semi-empirical model for phase composition of water in clay-water systems. Cold Regions Science and Technology, 49(3), 226-236. https://doi.org/10.1016/j.coldregions.2007.03.013

[16] Kozlowski, T. (2009). Some factors affecting supercooling and the equilibrium freezing point in soil-water systems. Cold Regions Science and Technology, 59(1), 25-33. https://doi.org/10.1016/j.coldregions.2009.05.009 
[17] Wang, D. Y., Zhu, Y. L., Ma, W., \& Niu, Y. H. (2006). Application of ultrasonic technology for physicalmechanical properties of frozen soils. Cold Regions Science and Technology, 44(1), 12-19. https://doi.org/10.1016/j.coldregions.2005.06.003

[18] Timur, A. (1968). Velocity of compressional waves in porous media at permafrost temperatures. Geophysics, 33(4), 584-595. https://doi.org/10.1190/1.1439954

[19] Kaopmans, R. W. R. \& Miller, R. D. (1966). Soil freezing and soil water characteristic curves. Soil Science Society of America Journal, 30, 680-685. https://doi.org/10.2136/sssaj1966.03615995003000060011x

[20] McKenzie, J. M., Voss, C. I., \& Siegel, D. I. (2007). Groundwater flow with energy transport and water-ice phase change: Numerical simulations, benchmarks and application to freezing in peat bogs. Advances in Water Resources, 30(4), 966-983. https://doi.org/10.1016/j.advwatres.2006.08.008

[21] Bonacina, C. \& Comini, G. (1973). On the solution of the nonlinear heat conduction equations by numerical methods. International Journal of heat and Mass Transfer, 16(3), 581589. https://doi.org/10.1016/0017-9310(73)90225-1

[22] Comini, G., Giudice, S. D., Lewis, R. W., \& Zienkiewicz, O. C. (1974). Finite element solution of non-linear heat conduction problems special reference to phase change. International Journal for Numerical Methods in Engineering, 8(3), 613-624. https://doi.org/10.1002/nme.1620080314

[23] Nicolsky, D. J., Romanovsky, V. E., \& Panteleev, G. G. (2009). Estimation of soil thermal properties using in-situ temperature measurements in the active layer and permafrost. Cold Regions Science and Technology, 55(1) 120-129. https://doi.org/10.1016/j.coldregions.2008.03.003

[24] Brandl, H. (2006). Energy foundations and other thermoactive ground structures. Geotechnique, 56, 81-122. https://doi.org/10.1680/geot.2006.56.2.81

[25] Lai, J. X., Qiu, J. L., Fan, H. B., Zhang, Q., Hu, Z. N., Wang, J. B., \& Chen, J. X. (2016). Fiber Bragg Grating SensorsBased in Situ Monitoring and Safety Assessment of Loess Tunnel. Journal of Sensors, 2016, Article ID: 8658290. https://doi.org/10.1155/2016/8658290

[26] Islam, M. S., Fukuhara, T., Watanabe, H., \& Nakamura, A. (2006). Horizontal U-tube road heating sys-tem using tunnel ground heat. Journal of Snow Engineering of Japan, 22, 2328. https://doi.org/10.4106/jsse.22.229

[27] Islam, M. S., Fukuhara, T., \& Watanabe, H. (2007). Simplified heat transfer model of hori-zontal u-tube (HUT) system. Journal of Snow Engineering of Japan, 23, 232-239. https://doi.org/10.4106/jsse.23.232

[28] Adam, D. \& Markiewicz, R. (2009). Energy from earthcoupled structures, foundation, tunnel and sewers. Geotechnique, 59, 229-236. https://doi.org/10.1680/geot.2009.59.3.229

[29] Shao, F. Y. \& Yang, Z. Y. (1998). Anti-frost System and Construction of Dabanshan Tunnel. Railway Construction Technology, 1998(3), 40-42.

[30] Shao, F. Y. (1999). Construction Technology of Dabanshan Tunnel Cold Insulation Systems. Railway Construction, (10), 27-29.

[31] Liu, G. Y. (2001). Tunnel construction technology for the high altitude and the high and cold area. China Railway Science, 22(4), 50-55.

[32] Du, B. (2003). Construction Technique Research for High Elevtion Tunnel in Cold Weather. Chinese Journal of Rock Mechanics and Engineering, 22(Z1), 2453-2456.

[33] Liu, G. Y. (2006). The Frozen Soil Problems and Related Prevention Countermeasures of Dabanshan Highway Tunnel. Journal of Glaciology and Geocryology, 28(6), 833837.

[34] Hu, J. B., Qiao, C. J., Chu, Y. D., Ren, Y. B., \& Zou, Z. L. (2012). The Galongla Long tunnel waterproofing and drainage program design of Tibet Medog Highway. Highway, 3, 242-246.

[35] Liu, H. J., Zheng, J. Y., Chen, C. G., \& Huang, L. H. (2011). Rehabilitation project of the Dabanshan highland road tunnel. Journal of Chongqing University, 34(12), 138$143+150$.

[36] Lai, J. X. (2012). Experimental Study on Air Temperature Field for Cold-Region Tunnel in Qinghai-Tibet Plateau: A Case Study. Advances in Intelligent and Soft Computing, 141 AISC, 265-271. https://doi.org/10.1007/978-3-642-27957-7_33

[37] Xu, X. T. (2013). Study on Frostance, Anti-freezing and Drainage Technology of the Elashan Tunnel, Master thesis of Chongqing Jiaotong University, China.

[38] Li, Y. (2014). Study on Distribution of Temperature Field and Cold Insulation Technology on Tunnel in High Attitude and Cold Zones, Master thesis of Chongqing Jiaotong University, China.

[39] Liu, R. Q. (2014). Research of Setting Technology for Winter Protection Drainage Hole of Highway Tunnel in High Altitude and Cold Regions, Master thesis of Chongqing Jiaotong University, China.

[40] Luo, T., Wang, S. R., Zhang, C. G., \& Liu, X. L. (2017). Parameters deterioration rules of surrounding rock for deep tunnel excavation based on unloading effect. DYNA, 92(6), 648-654.

[41] Flores-Herrera, L. A., Sandoval-Pineda, J. M., Silva-Rivera, U. S., Tamayo-Meza, P. A., \& Rivera-Blas, R. (2017). CFD Simulation of Obstructed Ventilation Ports in a Subway Tunnel Section. International Journal of Simulation Modelling, 16(3), 386-198. https://doi.org/10.2507//JSIMM16(3)2.380

[42] Kostyuk, A., Kovtunenko, D., \& Kovtunenko, A. (2019). The Stress-Strain State of Horizontal Joints of Wall Panels. Tehnicki Glasnik-Technical Journal, 13(1), 7-11. https://doi.org/10.31803/tg-20180514083545

[43] Bian, B. (2014). Yan Kou Shan Tunnel Construction Method of Comprehensive Technical Research, Master thesis of Shijiazhuang Tiedao University, China.

[44] Li, G. P. \& Wei, Q. (2012). Waterproof and drainage design of highway tunnel in alpine region. Highway Tunnel, 2012(3), 43-45.

[45] Li, G. P., Yang, S. Z., \& Xi, W. Z. (2018). Safety Risk Assessment Technology of Yankou Mountain Tunnel in High Altitude and Cold Area. Journal of Catastrophology, 44(s1), 69-74.

[46] Zhang, X. Q. \& Guo, Y. P. (2014). Treatment technique of cave-in caused by deformation of the first branch of surrounding rock and replacement of arch in yankoushan tunnel. Highway Tunnel, 2014(2), 36-38.

[47] Guo, Y. P., Hu, J. Y., \& Wang, Y. L. (2012). Yankou mountain tunnel collapse treatment measures. Highway Tunnel, 2012(3), 54-55.

[48] Xuan, M. H. (2016). Research on the Thickness of Shotcrete Layer in the Initial Support of the Shallow Buried Section of the Yan Kou mountain tunnel. Value Engineering, 35(27), 79-82.

\section{Contact information:}

\section{Maolong ZHAO}

(Corresponding author)

Shaanxi Highway Group Co. LTD,

Xi'an 710075, China

E-mail: zhaomaol@126.com

\section{Wei ZHU}

Shaanxi Hengtai Highway Technology Co. LTD,

Xi'an 710075, China

E-mail: zhuwei2020719@126.com 